\title{
La crítica política a través de la simbiosis cuerpo-instalación-environments. Propuestas disconformes con el establishment contemporáneo.
}

\author{
Moisès José Gil Igual \\ Departament d'Escultura, Universitat Politècnica de València, Camí de Vera, s/n, 46022 València. moigiig@esc.upv.es. Passeig del \\ Comtat, $n^{\circ} 5,03820$ Cocentaina (Alacant).
}

\begin{abstract}
In this work is presented the political critic as base for communication through Contemporary Art. Proposals underlay in human body acting as members of sculptural environments and installations. These proposals are located in the public sphere with an urban context inside the framework of the city and the viewer as part of it, they should nurture the work with their own discursive interpretations translating themselves as part of the work. Since 60's human body is the absolute main character of the artistic movements, performing the place and media of social revindications. This text pretends to show distinct sculptural action lines pretending to use human body as a resource and platform to show a social revindication and solidarity message. Actual human beings perform, jointly technological advancements, new poetical and discursive lines with the aim of emphasize their preoccupation by themselves, the human being preoccupation. Contemporary human body representation will allow us to express contempt and political corruption opposition feelings, with the Art we want to canalize the artist social feelings.
\end{abstract}

Keywords: Artistic practices, Art and politics, corruption, society, installation, environments, mynimois.

\begin{abstract}
Resumen
En este trabajo se presenta la crítica al sistema político en base a la comunicación mediante el arte contemporáneo. Propuestas fundamentadas en el cuerpo humano actuando como miembros de instalaciones y ambientes escultóricos. Esta propuesta está situada en la esfera pública dentro de un contexto urbano en el marco de la ciudad y el espectador como parte de ella, éste nutre la obra con sus propias interpretaciones discursivas llevándolos a ser parte de la obra. Desde la década de los años 60 el cuerpo humano ha servido como protagonista de los movimientos artísticos, convirtiéndose como lugar y medio de las reivindicaciones sociales. Este texto pretende mostrar diversas líneas de acciones escultóricas pretendiendo usar el cuerpo humano como recurso y plataforma del mensaje de la reivindicación social y la solidaridad. El ser humano de nuestros días lleva a cabo, junto con los avances tecnológicos, nuevas líneas poéticas i discursivas con el objetivo de enfatizar la preocupación por ellos mismos, la preocupación del ser humano. La representación de un cuerpo humano contemporáneo nos permitirá expresar los sentimientos de desprecio y oposición a la corrupción política, mediante el Arte queremos canalizar el sentimiento social del artista.
\end{abstract}

Palabras clave: Prácticas artísticas, Arte y política, corrupción, sociedad, instalación, environments, mynimois. 


\section{Introducción.}

«El arte y el poder se necesitan, los países buscan asociar su imagen a las vanguardias artísticas» Catalina Serra. (Serra, 2008, 1)

Arte, poder político y sociedad, han ido, a través de la historia de la humanidad, íntimamente ligados desde las pirámides del antiguo Egipto las grandes obras se deben al poder político o religioso, pero debemos preguntarnos: ¿quien se ha servido de quién? En nuestra propuesta hemos analizado que ha sido la política la beneficiaria del arte, la que ha tenido la batuta y se ha servido del arte para multiplicidad de fines, pongamos por ejemplo desde los edificios políticos y religiosos tanto en Grecia como en Roma, así como las esculturas y pinturas (documentales) conmemorativas de batallas, o retratos, tanto públicos como privados de dignatarios que van desde bustos a estatuas de gran formato a figuras ecuestres. No podemos olvidar los miniados medievales, las iglesias y catedrales, así como los grandes cuadros de David y Gros sobre los triunfos en las batallas de Napoleón, pues este retrataba al más genuino estilo del reportero gráfico actual. Acercándonos al siglo XX nos encontramos con un arte sumido e imbricado y a la vez comprometido con causas revolucionarias, podemos observar cómo ha influido la técnica y las propuestas gráficas en los carteles en la propaganda política de la Revolución Rusa y la Mexicana, los carteles del nazismo alemán o los de la Guerra Civil española, con sus respectivas obras faraónicas como fue el caso del Valle de los Caídos y las representaciones escultóricas de los hombres y mujeres arios en la Alemania nazi así como las representaciones escultóricas en el espacio público de líderes como Hitler o Lenin y las alusiones escultóricas a la clase obrera en un caso y la raza aria en el otro.

No siempre el arte, o mejor: el artista, ha estado de acuerdo con las ideas y actos de su Rey mecenas, nos remitimos al caso de Francisco de Goya. En los retratos de la familia real, son particularmente definitorios el tratamiento del retrato psicológico que unido a la maestría de su técnica hacen que sus representaciones cobren un cariz peculiar en el resultado de las caras idiotizadas de los monarcas por los sucesivos incestos históricos y la consecuente degeneración de la raza asi como su limitada inteligencia y la nula capacidad de gobernar. (Figura 1)

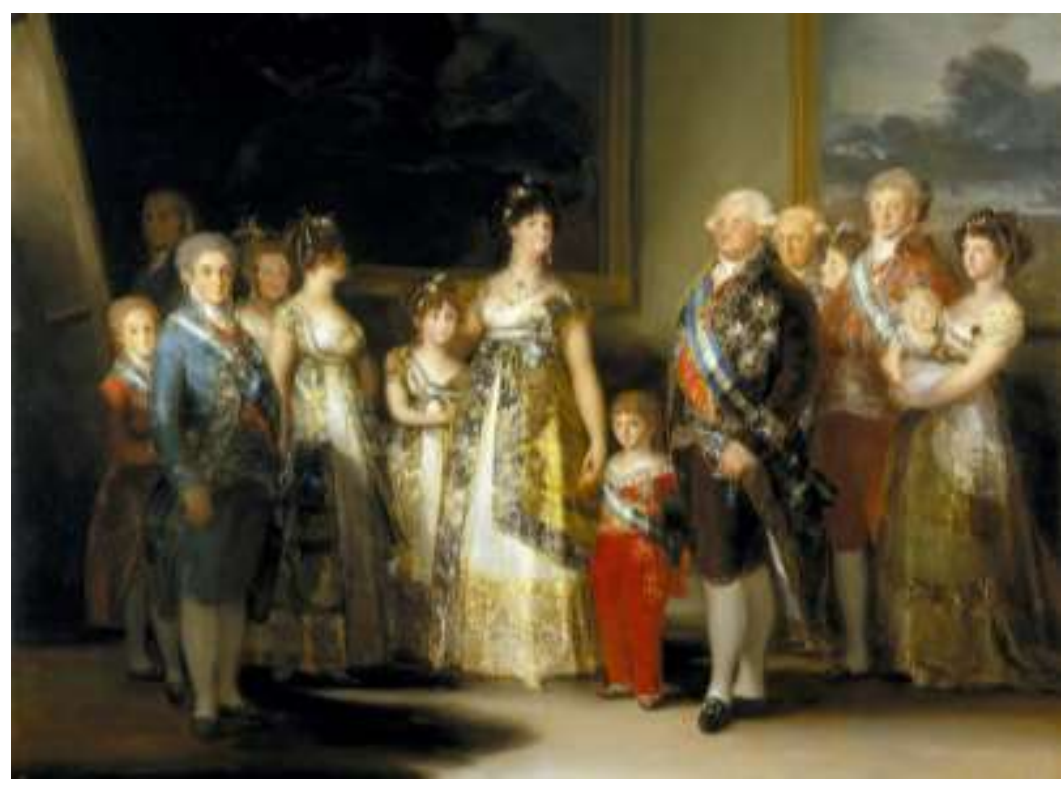

Fuente: Museo del Prado, Madrid.

< https://www.museodelprado.es/coleccion/obra-de-arte/la-familia-de-carlos-iv/f47898fc-aa1c-48f6-a779$71759 \mathrm{e} 417 \mathrm{e} 74>$

Figura 1. Francisco de Goya "La familia de Carlos IV” 1800. Óleo sobre lienzo. 280x366 cm.

Volviendo a la actualidad y sobre todo, a lo que los políticos hacen para poder ser objeto de ridiculización por medio del arte, aunque ellos mismos se retratan, no les hace falta nadie, tenemos como ejemplo la noticia, que con sarcasmo e ironía reflejan algunos sectores de la prensa, cuando se trata de una dejación de funciones o se trivializa sobre hechos y 
acontecimientos o situaciones acuciantes para el ciudadano y su contexto, pero qué para el político, subido en su pedestal no le afectan, se sitúa por encima del bien y del mal. Tenemos el ejemplo: cuando Mariano Rajoy, siendo vicepresidente del ejecutivo de J.Ma . Aznar, trivializó sobre los vertidos del hundimiento del petrolero "Prestige" cuando habló de hilitos de plastilina de estiramiento vertical que salían de las bodegas del barco frente a las costas de su tierra natal, Galicia.

«Rajoy trivializó al hablar de “hilillos de plastilina” y no calibró las consecuencias del hundimiento.» (Varela, 2013, 2)

En este caso, lo que más nos llama la atención es la fotografía (Figura 2A) que ilustra esta noticia en un acto de depuración de responsabilidades la actitud que muestra es insensata y desatinada consigo mismo e imprudente con los ciudadanos. En otro medio, "El Español" (Cebreira, 2017) trataban la noticia vista desde el punto de vista anticipativo y previsible a modo de reportaje monográfico y lo que nos sorprende, aparte del contenido de la noticia son las ilustraciones (Figura 2B) en el que aparece con cara de no haber roto nunca un plato y diciendo lo de los "pequeños hilitos" que se convirtieron en 125 toneladas de fuel al día y previsor, como siempre, aseguró que: "la marea (negra) no va a llegar a las Rías Baixas". (Cebreira, 2017) Vemos en la imagen la típica cara de que "con él no va la cosa” de buenazo sorprendido.

Se plantea el representar por medios tridimensionales y aportando nuevas estrategias artísticas el apostar por activar una serie de actividades fundamentadas en la crítica a las clases opulentas, políticos y demás oportunistas que alardean de defender al ciudadano, pero más bien es todo lo contrario, nos tienen en un limbo de supuesta democracia, está, pues, en nuestro objetivo, aportar nuestro grano de arena por medio de la creación activa de arte y su respectiva reflexión así como el posicionamiento por parte del espectador, de lo que nos transmite la propia actualidad reflejada en la prensa, televisión,
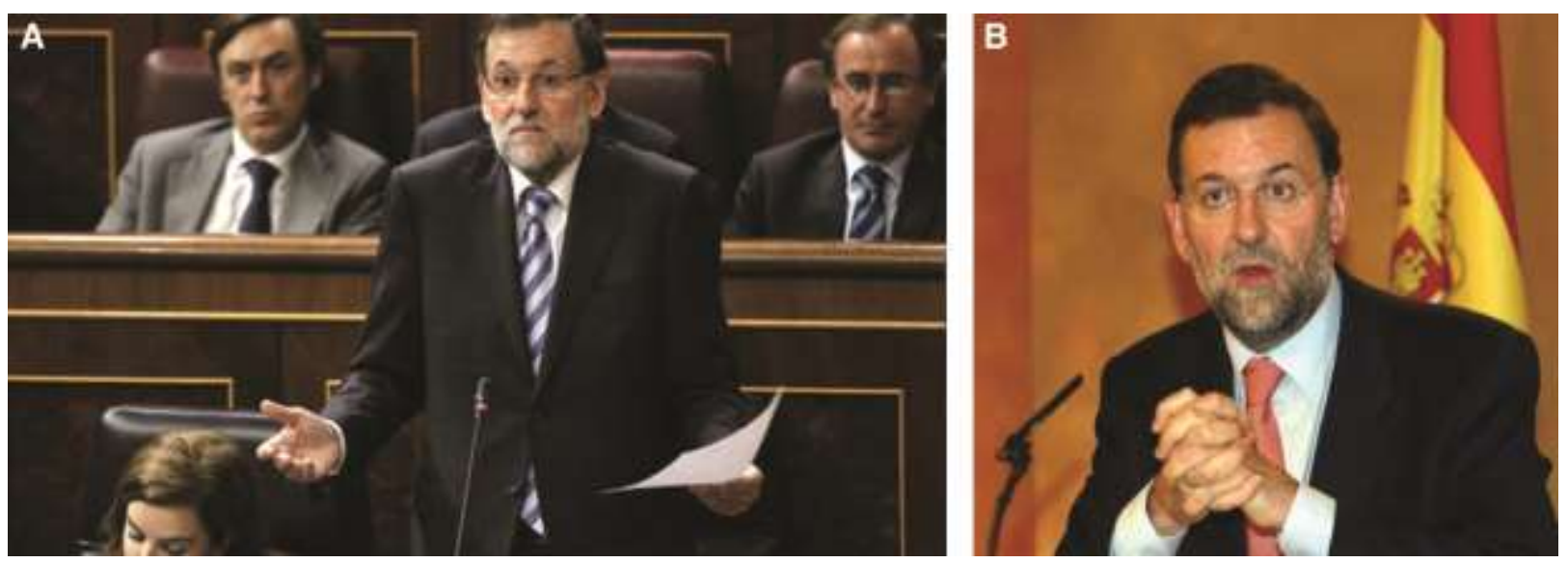

Fuentes: Agencia EFE, El Español.

Figura 2. A Mariano Rajoy, en el congreso de los diputados, B Mariano Rajoy, en rueda de prensa por el caso prestige.

Reportajes, etc. unido a las vivencias diarias. Dejar constancia de hechos reales destacados por su flagrante desvergüenza, inmoralidad y continua provocación a la sociedad civil extraídos tanto de sentencias judiciales, diarios de sesiones o crónicas en los diversos medios. Todo esto se realiza con el fin de no volver a cometer los mismos errores, de evitar que la historia se repita.

\section{Desarrollo.}

«El arte político es el que trabaja sobre las consecuencias de su existencia, de sus interacciones, ...» Tania Bruguera. (Bruguera, 2019, 11) 
La actualidad, por el mero hecho de serla, se ve abocada al ostracismo, pues depende de la rapidez e inmediatez con la que nos llega a nuestro alcance la información por lo que compiten los medios, produciendo el efecto de no perdurabilidad de la noticia en la memoria, pues al poco sale otra que la solapa.

Dado el grado de despropósitos y excentricidades por parte de los protagonistas de las noticias, los centramos en el poder político y económico pues en la toma de decisiones de estos, está el futuro bienestar social y una sana democracia.

Como si de un mal generalizado y de asimilación convencida por la sociedad, esas decisiones han provocado sucesivos escándalos, abocándonos al abismo, lo incorrecto, el caos y la inestabilidad social, etc. en cada uno de los casos que nos dan a conocer por los diversos soportes de canalización y difusión de la información. Estos nos sirven de puntos de partida para este proyecto.

El hecho de cerrar, precintar e incluso, encadenar a estos esperpentos de la vida sociopolítica-económica, en una propuesta de simulacro de las intenciones sociales de la repercusión de sus actos y decisiones. (figura 3, A y B).

Lo que más incide en nuestra sensibilidad es que se nos tome por ignotos manipulables y fiel servidumbre a los antojos aleatorios de esta gente que no hemos tenido más remedio que elegir. Se van ultrajando las libertades individuales, las desigualdades sociales y judiciales son cada vez más insultantes, la ciudadanía encuentra que sus esfuerzos son en vano, que los esfuerzos de sus padres y abuelos en pro del bienestar y los logros sociales involucionan a marchas forzadas.

La política se ha servido del arte y viceversa, pero debemos concienciarnos, como artistas y consumidores de arte, que éste debe estar al servicio de la sociedad que es a quien va dirigido, planteando nuevas perspectivas teóricas y metodologías que aporten resultados dinámicos, generar un arte puro de razonamiento legítimo social que incite al espectador a abandonar la recepción pasiva y complaciente. Un ser humano descontaminado de hipótesis y quimeras producidos por los bombardeos visuales de los mas-media.
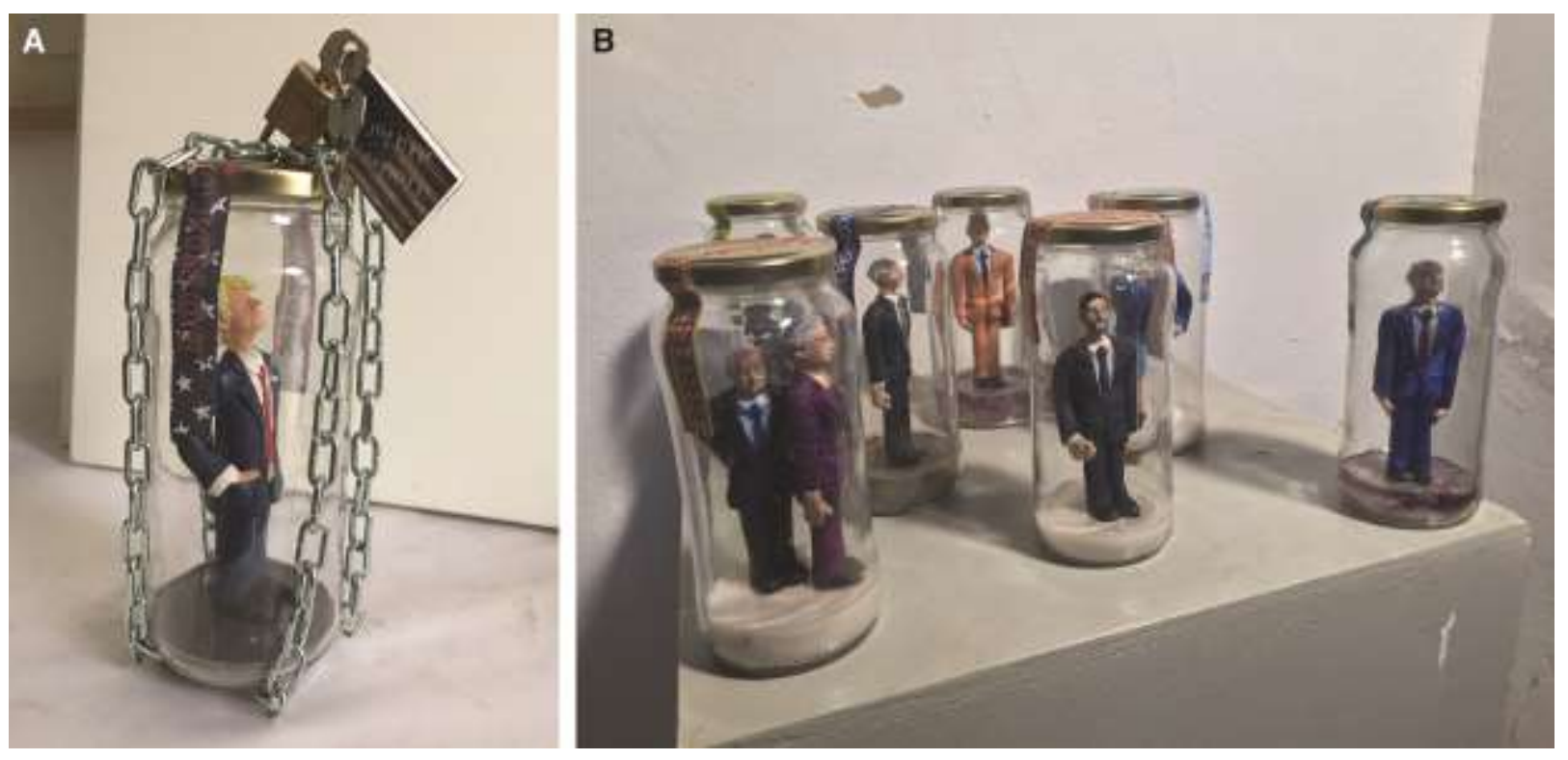

Fuente: el autor

Figura 3. B "Not open, very dangerous", 2017 Resina de polyester, cadena, candado, papel y frasco de cristal, $18 \times 9 \varnothing \mathrm{Cm}$. B, "Misatges dins d'un pot” 2016. Resina de polyester y frascos de cristal, medidas variables.

El olvido de la información dada por la velocidad en el acontecimiento de las noticias deriva en la caída del interés global. Este es un factor muy a tener en cuenta en esta propuesta. Podemos encontrar varias causas que nos obligan a retener en 
la memoria con el fin de no volver a reincidir en los errores propios como: los abusos de poder, la corrupción, las negligencias, intencionadas o no.

\section{Primer caso.}

Uno de los ejemplos prácticos se base en la negación a lo evidente, "cuando alguien molesta, se le aparta" como si de una mafia u organización criminal se tratara. Tenemos los ejemplos claros de los jueces Garzón, Silva, Ruz y Castro, recordaremos los casos en una muestra de los titulares aparecidos en la prensa, olvidados por la mayoría de ciudadanos:

«Jueces progresistas denuncian ante la ONU presiones del Gobierno contra la independencia judicial» (Moya, 2017, 14) «Garzón dice adiós a la carrera judicial al ser condenado a 11 años de inhabilitación. La sentencia, además, le expulsa de la carrera judicial y le obliga a pagar a los abogados de los corruptos de la red Gürtel» (Lázaro, 2015, 8) «El Supremo ratifica la condena al juez Elpidio Silva por prevaricar en el 'caso Blesa» (Marraco, 2015, 10) «El Supremo confirma la inhabilitación de 17 años del juez. Elpidio Silva» (Martín, 2015, 4)

A simple vista, estos titulares nos muestran el ejercicio judicial en nuestro país. No debemos sospechar de las sentencias, pero podemos y debemos discrepar de estas, evidentemente lo hacemos con las herramientas de las que disponemos, las propuestas plásticas.

Con el fin de que las propuestas escultóricas lleguen al espectador de forma directa, clara y concisa, debemos ser explícitos en los contenidos estéticos, conceptuales y reales. En este primer caso: se plantea es aislamiento de los jueces, en su día llamados "estrella", subidos en pedestales, de madera y quemados en su base y envolviéndolos un alambre de espinos (Figura 4A), para que no se muevan, que callen, “que no molesten”, sobre un terreno seco, donde había agua en un pasado, un agua como elemento de cordura, renovación y de vida, pero esencialmente de libertad.

Nos cuestionamos aquí la independencia del poder judicial, si ésta es real y si: existen presiones a fiscales y jueces, para la imputación, aperturas de causas, investigaciones, etc., ¿los poderes gubernamentales colaboran de forma abierta con la justicia?, ¿hay jueces y fiscales partidistas?, ¿cómo se debería plantear la Justicia?, ¿existe la coacción judicial?, estas preguntas y un sinfín más nos vienen a la mente cuando recordamos casos flagrantes que han protagonizado los personajes elegidos para la ejecución de esta propuesta escultórica “Segle XXI?”. (Figura 4B).
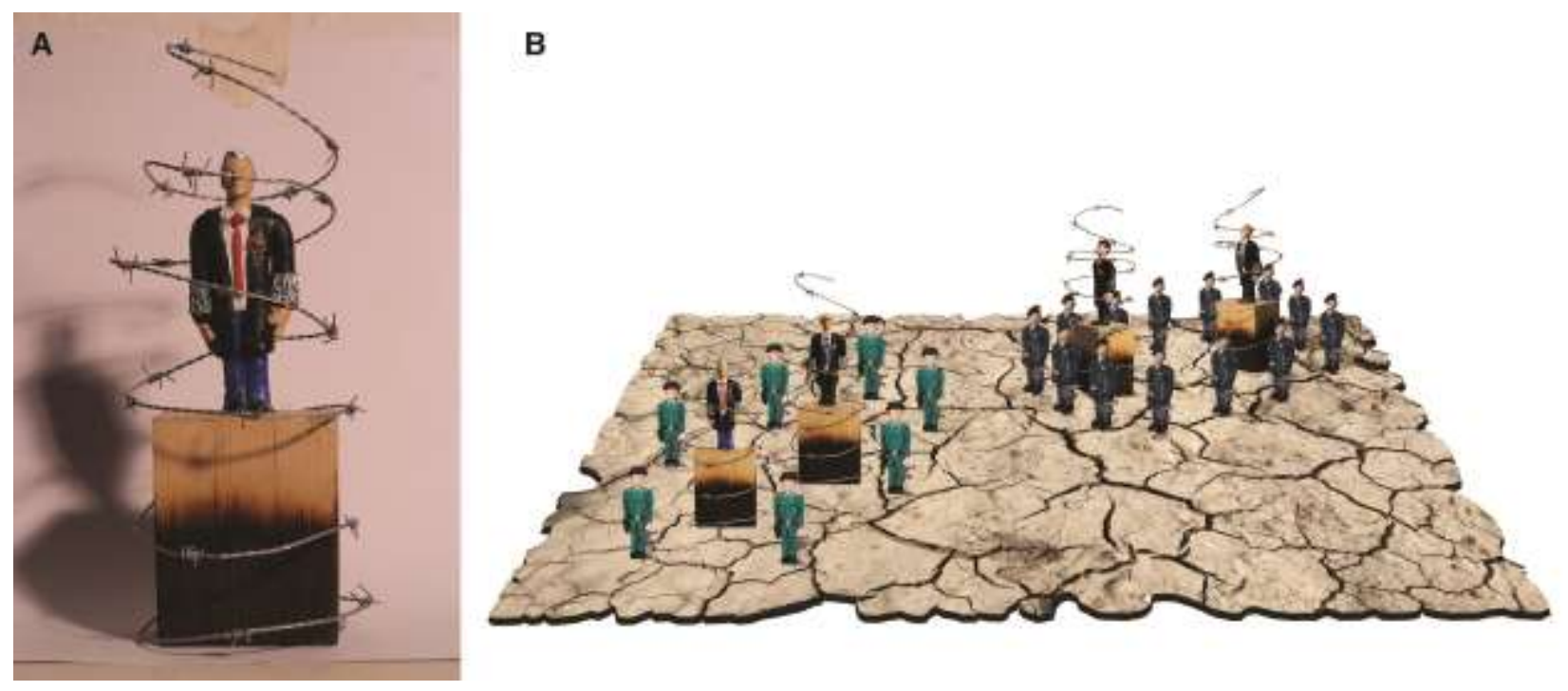

Fuente: el autor

Figura 4. A “Juez Castro", 2015. Resina, madera y alambre de espinos, 28x14x15 Cm. B, Instalación: “Segle XXI !!!” 2016 Resina, madera, alambre de espinos y pasta de estuco. medidas variables. 


\section{Segundo caso.}

Este tema nos persigue desde que el ser humano se convirtió de nómada en sedentario, tratamos de la migración, uno de los más trágicos y dramáticos acontecimientos que está sufriendo la humanidad que nos perturban los más elementales instintos de convivencia, supervivencia, compasión, solidaridad. En nuestra memoria sigue presente ya que nuestro país ya sufrió de este mal, pero parece que no nos acordamos. Como cualquier artista comprometido, nos vemos obligados a tratar este tema en el proceso de investigación: las políticas de la UE acerca de la migración en la actualidad.

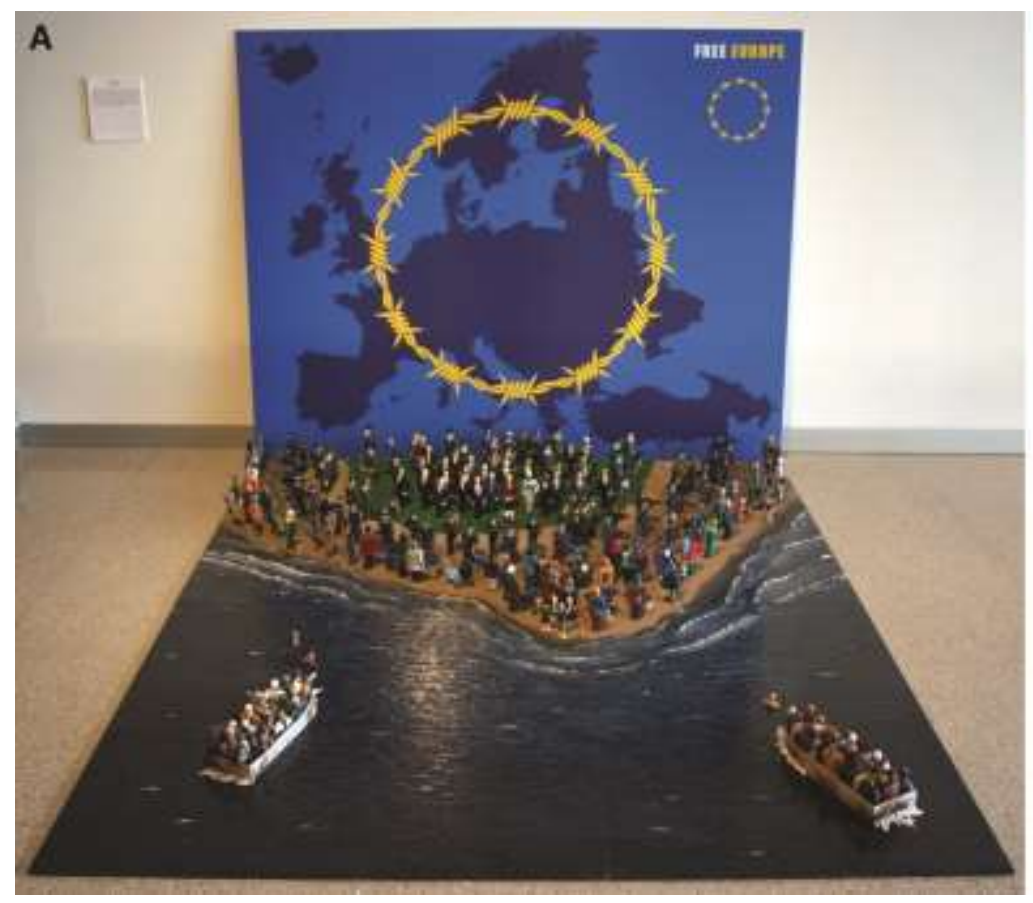

Figuras 5 (A, B i C). "Free Europe" 2018. Resina, madera, alambre de espinos y arena. 200x170x200 Cm.

«Italia y Malta impiden el desembarco de 629 inmigrantes rescatados en el mar» EFE. (2018) «El Gobierno elude acoger refugiados pese a tener más de 600 plazas libres» (Bayona, 2017, 5) «Más de 500 migrantes permanecen bloqueados en el Mediterráneo» Cordero, 2019. Pag.1) «Italia impide desembracar al “Open Arms” pese al pacto de seis países para acoger a los migrantes» (Abellán, 2019, 3).

Europa, que tanto se prodiga en ser la defensora a ultranza de los Derechos Humanos, y que se congratula de estar al lado de los más débiles, resulta que de facto la actuación europea sobre la diáspora migratoria no es como se preveía. ¿Elude su responsabilidad de solidaridad y cooperación con los más débiles y/o en enclaves conflictivos? Con el fin de que cada cual extraiga sus propias conclusiones, damos fe por medio de la instalación "Free Europe" 2018. (Figura: 5) 


\section{Tercer caso.}
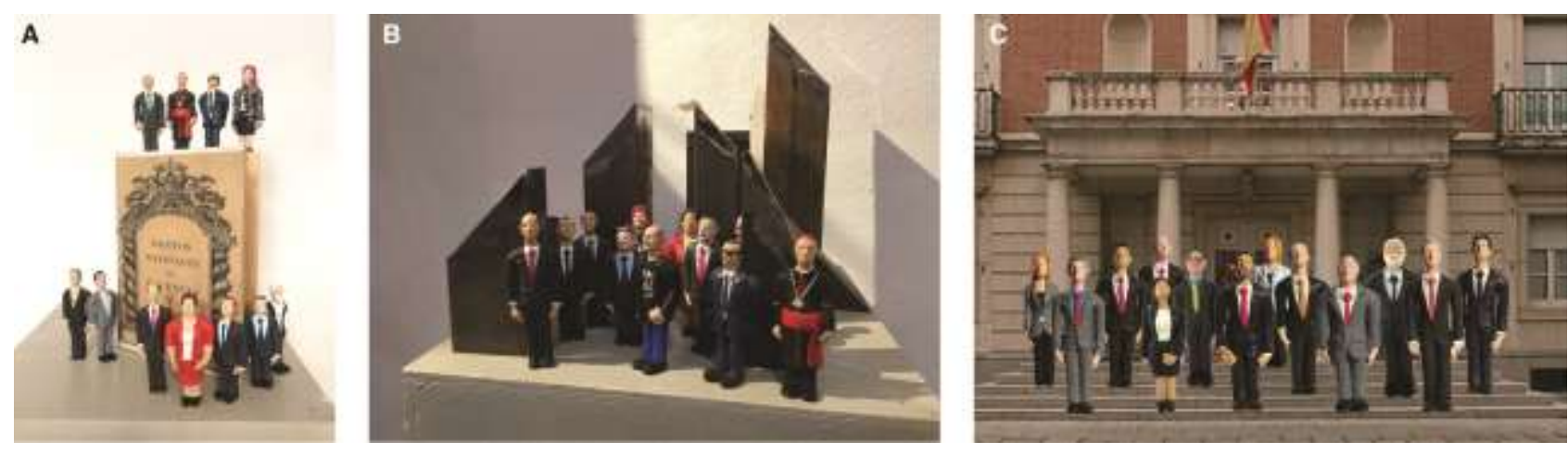

Fuente: el autor

Figura 6. A "Tots menys ú. País Valencià, País de Corrupció" 2015, medidas variables, acero, polyester papel y latex B "Santos Patrones de Valencia, Tomo I “. 2014, medidas variables, madera, polyester papel y látex y C I després, a la taula i al llit, al primer crit. 2014. Instalación virtual, medidas variables.

En el intento de desgranar o intentar entender los mecanismos de poder en nuestro país y a los políticos españoles, nos vemos obligados a ocupamos de la política nacional, dado que es uno de los temas que más directamente nos atañen en primer lugar nos centramos en la visión que tenemos de nuestros políticos, pero sobre todo la percepción y la confianza que nos transmiten a través de la mímica facial y el lenguaje no verbal de la gestualidad, las posiciones que ocupan en la foto, al lado de quien está cada cual, etc. Les retratamos en una foto típica como es la de la salida de Zarzuela tras la toma de posesión o los viernes fatídicos donde se tomaban una serie de decisiones por decreto ley, que sólo servían para ahogar más a las clases medias y bajas. La ciudadanía temblaba cuando llegaban los viernes para ver qué y donde han decidido aplicar el recorte. (figura 12).

\section{Cuarto caso}

Otro planteamiento ha sido la de realizar una serie de propuestas donde empiezan a desarrollarse y hacerse eco, de los casos más flagrantes de la corrupción. Los ciudadanos nos vamos enterando poco a poco de sumarios, imputados "investigados" y sospechosos de haber metido la mano y que están implicados en el expolio del país, el robo al ciudadano. El ciudadano se siente traicionado por los políticos.

En nuestro caso, nos hemos centrado especialmente en la Comunidad Valenciana (Figura 6) por varias razones: la primera, principal y vinculante es el sentirme estafado por la trama octópoda central desde donde los tentáculos inoculan una especie de virus de la corrupción, donde aquello que toca, aquello que se contamina de corrupción, pero sobre todo llegan a convertirse en los políticos corruptos más deshonestos y avariciosos de España

La segunda razón ha sido por ser ciudadano valenciano, sentirme timado, tratado como un imbécil. Esta cantidad de sinvergüenzas no se merecen tener un lugar en ninguna obra de arte, ni tan siquiera en un retrato institucional, salvo en nuestro caso y para su vergüenza y escarnio público: su ubicación privilegiada en una obra de arte y que se hable de ellos de por vida de las barbaridades que hicieron. Este es, bajo nuestro punto de vista, el único correctivo que podemos conferirles desde el punto de vista y del buen hacer del artista comprometido con el entramado social que le rodea. 


\section{Quinto caso.}

Pocas cosas han cambiado desde antaño entre la clase dirigente, los caciques post-tecnológicos y otros seres que como garrapatas viven del sudor de su paisano, es evidente que no nos pueden quemar ${ }^{1}$, solo faltaría, se quedarían sin recursos para darse la gran vida y sin saber a quién joder. Los poderes fácticos están presentes y por encima del bien y del mal en todo momento, además de estar protegidos por la ley, (se proclama desde todos los ámbitos que todos somos iguales ante la ley, lo que es muy dudoso según Ignacio Escolar) pero lo que de verdad va en detrimento del ciudadano es que se auto imponen y disfrutan de "Patente de Corso" hacer lo que quieran con total impunidad sin escuchar al pueblo.

«¿Iguales ante la ley? La ley no dice eso» (Escolar, 2019, 5)

Nuestro interés estriba en documentar el presente, para ello se han generado estos pequeños referentes figurativos para así crear unos environements. Muy alejados del caricaturismo, lo anecdótico o lo banal y profundizando más en lo sensitivo y en lo que afecta al ser humano tan solo por el mero hecho de serlo. El tema tratado es denigrante, ver las miserias de los seres humanos transformadas en el deseo de poder asociado con el de la riqueza, son la vergüenza de la especie humana de la peor calaña perteneciente a una estirpe a extinguir. (Figura 7).

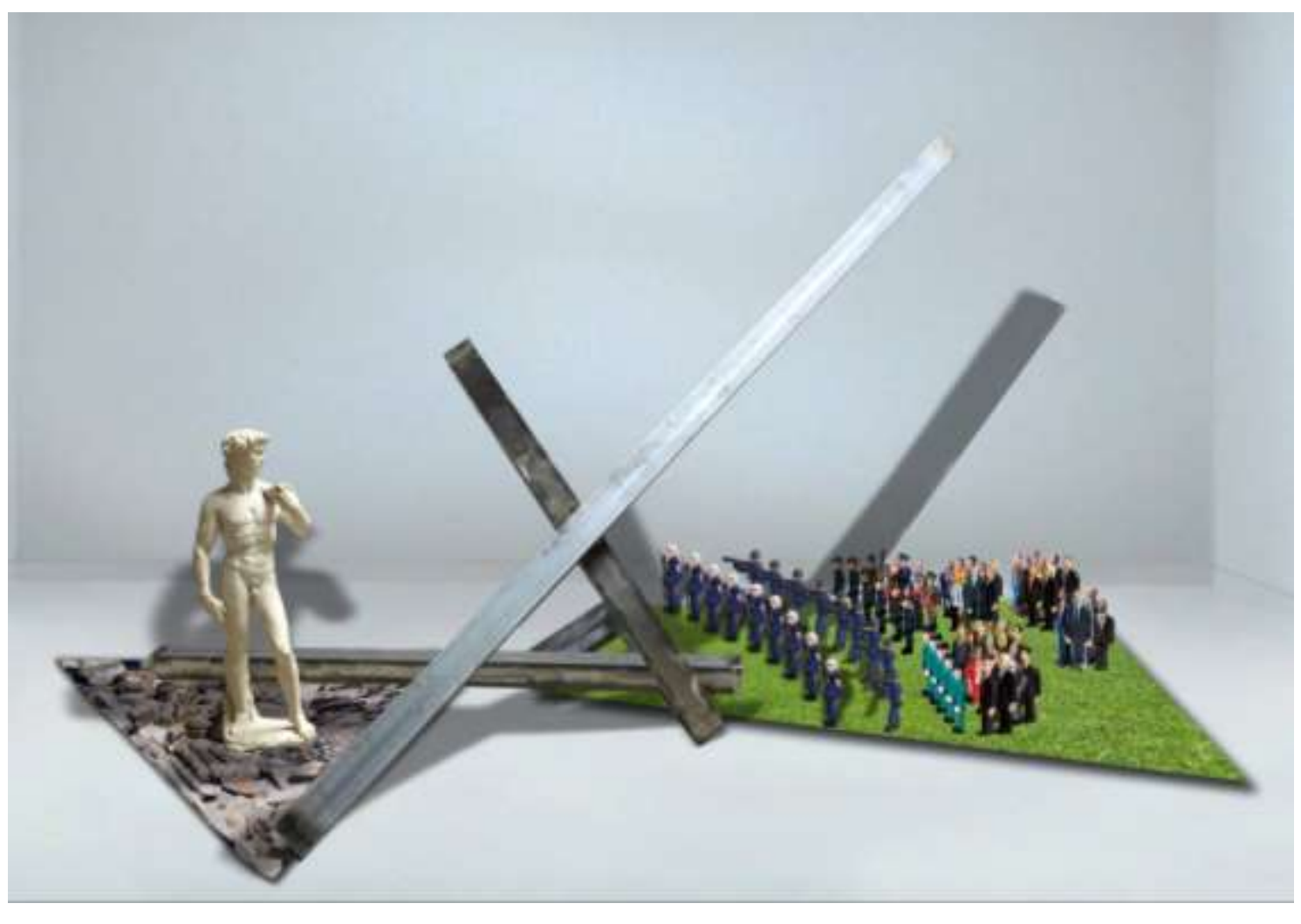

Fuente: el autor

Figura 7. David contra Goliat, Defensant l'espai privat. 2015. Fotomontaje de Instalación virtual.

\section{Unas reflexiones}

Lo que se pretende en esta forma de crear espacios escultóricos e instalaciones es conferir de significado social, reciente y coetáneo en el tiempo y próximo a nuestras sensibilidades en lo que respecta a la forma de pensar la obra. Dar fe y documentar de lo que ha pasado y está pasando en la política de nuestro país y en las zonas de interés general donde más se han vulnerado los derechos humanos. En nuestra intención está basar las propuestas en la reflexión y actitud del

\footnotetext{
${ }^{1}$ N.A: Entiéndase “quemar" en su forma metafórica.
} 
espectador frente a las diversas propuestas como si fuéramos documentalistas, periodistas tridimensionales, que tan solo relatamos los hechos para que el tercer actor los interprete y que no caigan en el ostracismo.

Abogamos por una Escultura-Documental política imparcial donde se ubica nuestra contemporaneidad social cuyo resultado se conserva en el espacio de las catedrales del arte donde adquieren un aura especial y convincente, y además una perdurabilidad en la memoria ya que, como dice Hegel:

"La perdurabilidad de la obra de arte no se basa en la permanencia del elemento sensible en el que se halla fijada... La obra de arte por el mero hecho de ser coseidad, perdura en el tiempo por su materialidad que le sirve de sostén... El sentido de la obra de arte es perdurable pero no inmutable." (Ramirez, 1988, 37)

La noticia al adquirir el estatus de obra de arte se convierte en perdurable en todos los sentidos, contextual, material, conceptual y sobre todo es un mensaje para generaciones futuras, que no caigan en lo que nosotros hemos permitido y que se han aprovechado esos cuantos para hacer lo que les venía en gana y a sus anchas.

Atestiguar la realidad de lo que acontece en el mundo a través de la obra del arte, del lenguaje no verbal de la escultura, la cual se perpetúa en el tiempo desafiando así la efimeridad de los medios de comunicación de masas

Testimoniar y fijar en el espacio - tiempo, el concepto, la poética, la idea, la intención semántica y la paráfrasis que acompaña a la obra, así como la esencia de las relaciones entre personajes - objetos - contexto; más la aportación critico - conceptual del espectador, el cual participará siempre y en cada una de las obras de forma activa, siendo un actor más, de igual o mayor importancia en el escenario de las propuestas (el espectador anotará en un bloc de papel que estará junto a la obra sus conclusiones y sus frases se irán añadiendo a la obra, estableciéndose como coautor de la obra de arte).

Se podría considerar que esta serie de esculturas son miniaturas, si atendemos a lo que Bachelard nos dice:

“Quienes crean objetos miniaturizados son en realidad soñadores innatos ... En la miniatura los valores se condensan y se enriquecen. La miniatura nos hace soñar, aunque pueda parecer algo insignificante. Además, es considerada como uno de los albergues de la grandeza”. (Bachelard, 1986, 185)

Con el fin de conseguir nuestros objetivos, se utilizan todos los mecanismos disponibles de puesta en escena y disposición espacial paralelas a las del mundo del espectáculo, del espectáculo de los mass-media, principalmente en el discurso televisivo, de su narratividad y con la utilización de estos recursos tanto técnicos como conceptuales ya que realmente queremos hacer arte que sea capaz de conseguir un impacto real sobre la política, o representar la política en arte.

"Si todos vivimos inmersos en una sociedad del espectáculo, aprovechemos la ampliación participativa de un arte problematizador, de discusión, incluso radical y subversivo”. (Mosquera, 2010, 89)

Siempre hemos tratado a la escultura como un vehículo transmisor de contenidos, de ideas, de intenciones, de proclamas, etc. con la intención comunicativa, para hablar con el espectador, establecer un diálogo con él, crear una empatía en base a la percepción de la obra y que nuestra propuesta no quede en saco roto y motive en el receptor una reacción. Utilizamos para ello los Minimoys, inocentes, infantiles, pero, como lo infantil, real, crudo: es verdad y se reflejan en propuestas escultóricas tal cual están las distintas situaciones sociales de nuestra contemporaneidad social económica y política que se tratan y en las que se basan nuestras propuestas.

"Cuando la política es la demencial práctica del recorte y el entierro vertiginoso de todos los derechos, resurge la necesidad insurreccional radical” (Castro, 2014, 137). 


\section{Referencias}

Abellán, L. (2016). “Así rechaza Europa a los refugiados sirios”. El País . (23 abril, 2016).

<https://elpais.com/politica/2019/08/15/actualidad/1565873223_058999.html> [consulta: 9 de septiembre de 2019].

BACHelard, G. (1986). La poética del espacio (2 ${ }^{\mathrm{a}}$ edición ed.). Mexico D.F.: Fondo de cultura económica.

BAYONA, E. (2017). "El Gobierno elude acoger refugiados pese a tener más de 600 plazas libres”. Público, edición de Zaragoza. (22 febrero, 2017). <https://www.publico.es/espana/gobierno-elude-acoger-refugiados-600.html> [consulta: 8 de septiembre de 2019]

Bruguera, T. (2017). “Árbol de Miradas”, en Quirós, L.F. diez años de controversia. <https://luisferquiros.wordpress.com/2017/11/09/10-anos-de-controversia/ > [consulta: 8 de septiembre de 2019]

CANTERA OrtiZ de Urbina, J. (2005). Refranero Latino. Madrid: Akal.

CASTRO, F. (2014). Arte y política en la época de la estafa global. Valencia: Sendemà.

CEBreiRA, B. (2017). "Las cartas secretas de los capitanes del prestige: la catástrofe anunciada 6 meses antes". El español. (11 noviembre, 2017) <https://www.elespanol.com/reportajes/grandes-historias/20171110/260974836_0.html> [consulta: 18 de agosto de 2019]

Cordero, A. (2019). "Más de 500 migrantes permanecen bloqueados en el Mediterráneo". France 24. (14 agosto, 2019$)<$ https://www.france24.com/es/20190814-500-migrantes-permanencen-bloqueados-mediterraneo> [consulta: 9 de septiembre de 2019]

EFE, R. (2007). "Malta impide de nuevo el desembarco del pesquero español con inmigrantes". El Mundo. ( 21 julio, 2007). <https://www.elmundo.es/internacional/2018/06/10/5b1d55f2468aeb8d1c8b458a.html> [consulta: 9 de septiembre de 2019]

Escolar, I. (2013). "¿Iguales ante la ley? La ley no dice eso". el Diario.es. ( 4 abril, 2013) <https://www.eldiario.es/escolar/Igualesley-dice_6_118348193.html > [consulta: 10 de septiembre de 2019]

LÁzARo, J.M. (2015). "Garzón dice adiós a la carrera judicial al ser condenado a 11 años de inhabilitación". El País. (10 marzo, 2015) <https://elpais.com/politica/2012/01/23/actualidad/1327315561_578421.html> [consulta: 7 de septiembre de 2019]

LEYvA, G. (2005). La teoría crítica y las tareas actuales de la crítica. Madrid: Antrhopos.

Marraco, M. (2015). "El Supremo ratifica la condena al juez Elpidio Silva por prevaricar en el 'caso Blesa". El Mundo. (23 abril, 2015) < https://www.elmundo.es/espana/2015/04/23/5538e363268e3e2d388b4578.html> [consulta: 8 de septiembre de 2019]

Martín, J. (2015). "El Supremo confirma la inhabilitación de 17 años del juez Elpidio Silva". El País. (23 abril, 2015) <https://elpais.com/politica/2015/04/23/actualidad/1429794748_755210.html> [consulta: 22 de septiembre de 2019]

Mosquera, G. (2010). Caminar con el diablo, textos sobre arte, internacionalización y culturas. Madrid: Exit edit.

MoYA, A. (2017). "Jueces progresistas denuncian ante la onu presiones del gobierno contra la independencia judicial". El plural. (9 febrero, 2017) <https://www.elplural.com/politica/jueces-progresistas-denuncian-ante-la-onu-presiones-del-gobierno-contra-laindependencia-judicial_99795102 > [consulta: 5 de septiembre de 2019]

PRESS, R. E. (2016). "Bruselas ofrece a los gobiernos pagar para eludir la acogida de refugiados". Europapress. (4 mayo, 2016) $<$ https://www.europapress.es/internacional/noticia-bruselas-ofrece-gobiernos-pagar-eludir-acogida-refugiados20160504120224.html> [Consulta: 14 de septiembre de 2019]

RAMIREZ LuQue, M. I. (1988). Arte y belleza en la estética de Hegel. Sevilla: S.P. Universidad de Sevilla.

Serra, C. (2016). "¿Arte para la política o política para el arte?" El País. (3 diciembre, 2016) <https://elpais.com/diario/2008/12/03/sociedad/1228258801_850215.html> [consulta: 24 de septiembre de 2019]

VARELA, F. (2013). "Rajoy trivializó al hablar de "hilillos de plastilina" y no calibró las consecuencias del hundimiento". infoLibre. (13 noviembre, 2013)

<https://www.infolibre.es/noticias/politica/2013/11/13/rajoy_trivializo_hablar_quot_hilillos_plastilina_quot_calibro_las_consecu encias_del_hundimiento_9768_1012.html> [Consulta: 7 de septiembre de 2019]

Velasco, F. (2015). "El juez Castro no podrá seguir en el juzgado tras la jubilación". La Razón. (18 febrero, 2015) <https://www.larazon.es/espana/el-juez-castro-no-podra-seguir-en-el-juzgado-tras-la-jubilacion-HG8866955> [Consulta: 4 de septiembre de 2019]

ZafrA, I. (2016). "El juez Ruz deja hoy la Audiencia rumbo a Móstoles". El País. (15 diciembre, 2016) <https://cincodias.elpais.com/cincodias/2015/04/16/economia/1429193958_492712.html> [Consulta: 20 de septiembre de 2019] 